\title{
The link between hypertension and preeclampsia/ eclampsia-life-long cardiovascular risk for women
}

\author{
Tamar Vakhtangadze ${ }^{1}$, Nino Gakhokidze ${ }^{3}$, Magda Khutsishvili², Salome Mosidze $^{2}$ \\ ${ }^{1}$ Research Institute of Clinical Medicine, Caucasus International University, Tbilisi 0113, Georgia. \\ ${ }^{2}$ Tbilisi State Medical University, Tbilisi 0186, Georgia. \\ ${ }^{3}$ Department Propedeutics of Internal Diseases, David Tvildiani Medical University, Tbilisi 0159, Georgia.
}

Correspondence to: Prof. Tamar Vakhtangadze, Research Institute of Clinical Medicine, Caucasus International University, Tevdore Mgvdeli street 13, Tbilisi 0113, Georgia. E-mail: tamarvakh@yahoo.com

\begin{abstract}
How to cite this article: Vakhtangadze T, Gakhokidze N, Khutsishvili M, Mosidze S. The link between hypertension and preeclampsia/ eclampsia-life-long cardiovascular risk for women. Vesse/ P/us 2019;3:19. http://dx.doi.org/10.20517/2574-1209.2019.07
\end{abstract}

Received: 30 Nov 2018 First Decision: 5 Feb 2019 Revised: 14 Feb 2019 Accepted: 15 Feb 2019 Published: 31 May 2019

Science Editor: Alexander N. Orekhov Copy Editor: Cai-Hong Wang Production Editor: Huan-Liang Wu

\begin{abstract}
Cardiovascular diseases remain the main cause of death and morbidity in women. Despite the active preventive measures and the reduction in the total number of morbidity and mortality rates, the rate of cardiovascular morbidity remains high in the population, moreover cardiovascular morbidity is increased in women of 35-54 years. Cardiovascular morbidity has several unique characteristics for women; pregnancy, gestational hypertension, preeclampsia/eclampsia are genderspecific risk-factors for further cardiovascular morbidity in women, it's possible to detect these risk-factors in younger age groups and start prevention as early as possible. Arterial hypertension, which is characterized by genetic polymorphism, is an important and a powerful risk factor for development of both acute and chronic cardiovascular diseases; association of arterial hypertension with different metabolic disorders suah as metabolic syndrome, diabetes seems particularly dangerous in pregnancy in terms of peri-pregnancy and life-long morbidity. Preeclampsia shares some common features with atherogenesis and metabolic changes and atherogenesis and metabolic changes, so presence of hypertension during pregnancy increases the risk of cardiovascular diseases and diabetes later in the life. Is pregnancy revealing or predisposing factor of development cardiovascular diseases is not still clear and to answer these questions more and more studies are required.
\end{abstract}

Keywords: Arterial hypertension, women, pregnancy, cardiovascular risk

\section{INTRODUCTION}

Cardiovascular diseases remain the main cause of death and morbidity in women ${ }^{[1,2]}$. Despite the active preventive measures and the reduction in the total number of morbidity and mortality rates, the rate of

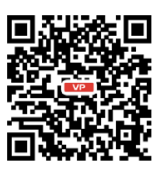


cardiovascular morbidity remains high in the population, moreover cardiovascular morbidity is increased in women at 35-54 years ${ }^{[3]}$. Arterial hypertension is an important, powerful risk factor for cardiovascular acute episodes, is characterized by genetic polymorphism ${ }^{[4]}$; association of arterial hypertension with different metabolic disorders - metabolic syndrome, diabetes is particularly dangerous ${ }^{[5]}$. Moreover, it was found that haemorrhage and hypertensive disorders are major contributors to maternal deaths in developing countries $^{[2]}$.

Preeclampsia/Eclampsia is a multiorgan syndrome associated with pregnancy, which occurs in $2 \%-8 \%$ of pregnant women ${ }^{[6-9]}$. The main characteristics of preeclampsia/eclampsia are pregnancy and elevation of blood pressure. It is considered that the arterial hypertension in pregnancy is clearly associated with cardiovascular morbidity during lifetime $\mathrm{e}^{[1,6,7,10,11]}$.

Preeclampsia/Eclampsia develops in 3\%-5\% of pregnancies in developed countries and $7.5 \%-8 \%$ of all over the world ${ }^{[9,12-14]}$. Preeclampsia/eclampsia is clearly linked to gestational age, offspring baby weight, nulliparity, etc. The cohort research study in Denmark of 536419 female has shown that delivery at 32-36 weeks of pregnancy increases the risk of next early premature labor from $2.7 \%$ to $14.7 \%$, and the risk of preeclampsia from $1.1 \%$ to $1.8 \%$. This study also showed that the first childbirth up to 28 weeks of pregnancy increases the risk of premature labour at next pregnancy by $26 \%$ and the risk of development of preeclampsia by $3.2 \%$. Preeclampsia during first pregnancy increases the risk of preeclampsia during next pregnancy from $14.1 \%$ to $25.3 \%$. Other studies also confirm that there are 3 times rise of cardiovascular morbidity and 7 times the incidence of hypertension in this group of population ${ }^{[15,16]}$.

Excessive weight, hypertension before pregnancy, age, metabolic disorders before pregnancy increases the risk of development of preeclampsia ${ }^{[6,17,18]}$. On the other hand, preeclampsia is clearly associated with the development of metabolic disorders in life, so it is not surprising that women with preeclampsia and eclampsia have a higher risk of cardiovascular morbidity.

\section{DEFINITON OF HYPERTENSIVE DISORDERS DURING PREGNANCY}

Hypertension in pregnancy comprises ${ }^{[19]}$ :

- Pre-existing hypertension: precedes pregnancy or develops before 20 weeks of gestation. It usually persists for more than 42 days post-partum and may be associated with proteinuria.

- Gestational hypertension: develops after 20 weeks of gestation and usually resolves within 42 days postpartum.

- Preeclampsia: gestational hypertension with significant proteinuria $(>0.3 \mathrm{~g} / 24 \mathrm{~h}$ or Albumin/creatinine ratio $\geq 30 \mathrm{mg} / \mathrm{mmol}$ ). It occurs more frequently during the first pregnancy, in multiple pregnancy, in hydatidiform mole, in antiphospholipid syndrome, or with pre-existing hypertension, renal disease, or diabetes. It is often associated with foetal growth restriction due to placental insufficiency and is a common cause of prematurity.

- Pre-existing hypertension plus superimposed gestational hypertension with proteinuria.

- Antenatally unclassifiable hypertension: this term is used when BP is first recorded after 20 weeks of gestation and hypertension is diagnosed; re-assessment is necessary after 42 days post-partum.

Preeclampsia and eclampsia develops before, during and after delivery. It may be firstly developed in the postpartum period, accompanied by manifestations of severe multiorgan impairment. Late postpartum eclampsia can be manifested with severe brain, heart, pulmonary artery impairment in postpartum $\operatorname{period}^{[20]}$.

European Society of Cardiology considers arterial blood pressure 140-159/90-109 mmHg as mild and $160 / 110 \mathrm{mmHg}$ as severely elevated for pregnant women, what is in agreement with other societies as well ${ }^{[6,19,20]}$. 


\section{Risk - factors}

The risk factors for preeclampsia and eclampsia are: nulliparity, family history of preeclampsia, multiple gestation, history of diabetes and hypertension, hypertension during pregnancy, rapidly growing hydatidiform mole, mother's age, antiphospholipid syndrome, impaired glucose tolerance, caesarean delivery, race ${ }^{[6,8,21-23]}$. There is evidence that women who smoke are less likely to develop eclampsia, although the reason is not clear ${ }^{[24]}$. Almost all these risk-factors are linked to cardiovascular diseases as well (hypertension, impaired glucose tolerance, age, inflammatory profile, race, etc.).

Systematic review and meta-analysis of cohort studies of 25,356,688 pregnancies among 92 studies out of 27 countries $^{[25]}$ has shown, that the risk of development of preeclampsia is clearly linked to antiphospholipid antibody syndrome, prior preeclampsia, chronic hypertension, pregestational diabetes, assisted reproductive technology, and BMI > 30. These factors are strongly associated with a high rate of preeclampsia, and presence of any of them will help to reveal the woman with "high risk" of preeclampsia.

\section{Clinical characteristics}

Patients with preeclampsia/eclampsia may develop following complaints ${ }^{[26,27]}$ : headache, seizures, visual disturbances (blurred vision, migraine - blinking scotoma), changed mental status, blindness cortical or retinal, shortness of breath, dyspnea, edema, epigastric or pain in the upper right corner of the abdomen, weakness, inability, may be presented signs of haemolytic anemia. It is noteworthy that eclampsia may be developed without prodromal symptoms ${ }^{[28,29]}$.

For a long time it was considered that eclampsia follows the pregnancy, but in recent years information about late (postpartum) eclampsia is growing, and more and more cases of late eclampsia are described and presented. Different authors describe different frequencies of late eclampsia, although the number of complications is not small and varies from $0.3 \%$ to $27 \%{ }^{[30,31]}$. Almost half of eclampsia cases develop after childbirth $^{[13,32]}$. Seizure is predominantly developing in the first 48 hours after childbirth, although it may occur even at 60 day ${ }^{[18]}$.

Whether early and late preeclampsia/eclampsia have the same pathophysiological mechanisms is not clear. Since pregnancy contains cardiovascular and metabolic stress, response to this stress may represent a woman's personal risk during lifespan, such serious and dangerous complication as venous thromboembolism and pulmonary thromboembolism among others ${ }^{[33]}$.

Late onset postpartum preeclampsia differs clinically from antepartum eclampsia. Thus study conducted on 194 patients with eclampsia (92 antepartum and 92 postpartum) showed, that patients with postpartum preeclampsia were older, multiparous and of lower socio-economic status than patients with antepartum preeclampsia, additionally, patients with postpartum preeclampsia have more clinical symptoms like headache, elevated blood pressure, abnormal vision, nausea/vomiting, seizures, shortness of breath and pedal edema, they also show significantly higher laboratory markers, than patients with antepartum preeclampsia. And additionally, they more often require blood pressure treatment after discharge ${ }^{[34]}$.

It is known that eclampsia and preeclampsia increases the risk of cardiovascular morbidity at 2-4 times in lifetime and reaches the level of risk related to tobacco consumption ${ }^{[3]}$. In this group of population is manifested life-long increase of incidence of arterial hypertension and metabolic disorders. Thus, after two years of observation of women with preeclampsia and eclampsia had been shown the increase the risk of cardiovascular disease ${ }^{[11]}$; Hypertension during pregnancy is associated with rise of 10 year cardiovascular risk in women ${ }^{[35]}$, women with preeclampsia who remain having hypertension after delivery have a twofold rise of risk of developing CVD in the next 10-30 years ${ }^{[36]}$, particularly during their fifth decade ${ }^{[37]}$. That's why 
the American Heart Association is considering eclampsia and preeclampsia as gender-specific risk factors of $\mathrm{CVD}^{[3]}$.

Preeclampsia itself is the risk factor for the other complications, including life-threatening complications. A population based study conducted in Sweden of 1,003,489 deliveries showed that preeclampsia, multiple childbearing, caesarean deliveries are important risk factors for pulmonary embolism and stroke ${ }^{[33,38]}$; On the background of preeclampsia increases the incidence of pulmonary embolism and stroke 3-12 times in late pregnancy, at delivery, and in the puerperium, and similar increases in risks were also observed for multiple pregnancies and caesarean delivery. At the time of pregnancy physiologically develops hypercoagulation state, rise of $\mathrm{D}$-dimer; continuous rise of these markers can lead to or is associated with vein thrombosis and pulmonary thromboembolism ${ }^{[39]}$.

Hypertension can occur firstly in postpartum period as well, the pathophysiology of this condition is not clear. In retrospective study of 988 women showed that women with postpartum hypertension have clinical risk factors and an antepartum plasma angiogenic profile similar to those found in women with preeclampsia what could be sign of subclinical or unresolved preeclampsia ${ }^{[40]}$.

Development of hypertension later in the life seems is clearly linked to complications and hypertension during pregnancy; thus a population-based study of 146,748 women showed that hypertension during pregnancy was associated with an elevated risk of future CVD or hypertension during life-time, irrespective of time of development of hypertension ${ }^{[4]}$.

\section{Physiology}

Normal physiologic changes during pregnancy are expressed in rise of cardiac output (CO) up to $20 \%-50 \%$ starting by 6 week of gestation and reaching maximum by 16-28 weeks (usually around 24 week); all of this is followed by rise of heart rate and stroke volume. It remains near peak levels up to 30 week $^{[42]}$. CO is rising by another 30\% during labor but then rapidly drops after delivery and reaches $15 \%-25 \%$ above normal level because of contraction of the uterus. Then continues gradual reduction (mostly over the next 3 to 4 weeks) and reaches the pre-pregnancy level at about 6 week postpartum. The rise of $\mathrm{CO}$ during pregnancy is mostly determined by increased requirements of the utero-placental circulation; Rise of cardiac output is determined also by the needs of skin to regulate the temperature and kidneys to excrete fetal wastes as well. Changes in cardiac function are associated with changes in renal function, thus glomerular filtration rate (GFR) rises by $30 \%-50 \%$, reaching maximum again by 16-24 week gestation, and remains at same level almost until term ${ }^{[42-44]}$.

Gestational Hypertension and Preeclampsia/Eclampsia are associated with impairment of cardiac function longer than in normal pregnancy. A prospective longitudinal case-control study showed that in one year postpartum, preeclampsia is associated with diastolic dysfunction, asymptomatic left ventricular moderatesevere dysfunction/hypertrophy, functional/geometric abnormality, which is even more expressed in women with preterm preeclampsia (56\%) than with term preeclampsia (14\%) or matched controls $(8 \% ; P<0.001)^{[45]}$, This study showed that majority of preterm preeclamptic women have stage B asymptomatic heart failure postpartum, and $40 \%$ develop essential hypertension within 1 to 2 years after pregnancy.

Fibrinoid necrosis with a perivascular mononuclear cell infiltrate vessel wall in early phase of preeclampsia, later lipophages are found in vessels of these women ${ }^{[46]}$. These changes are quite close to atherosclerotic process. Acute atherosis is not found in normal pregnancies including normal pregnancies in diabetic women, but can develop in vessels of women with preeclampsia or in women with small-for-gestational-age infants, or both.

Pregnancy leads to response from endocrine glands as well, partly because the placenta produces hormones and partly because most hormones circulate in protein-bound forms and this protein binding increases 
during pregnancy what affects response from endocrine glands. Thus, during pregnancy levels of estrogen, progesterone, thyroid hormones, aldosterone, cortisol are rising ${ }^{[47]}$, changes in insulin-resistance are developing. Each of these factors participate in atherogenesis and impairment of metabolic profile.

All above mentioned are well-known factors associated with normal pregnancy and impairment in one of them may have influence on others as well.

Preeclampsia (Eclampsia) is condition related to ischemia of placenta. There are studies that confirm the link between preeclampsia and gestational arterial hypertension with endocrine and metabolic diseasespreeclampsia is considered as a risk-factor of hypothyroidism, diabetes mellitus, and dyslipidaemia ${ }^{[48-50]}$. Each of them independently increases the incidence of cardiovascular morbidity.

Healthy pregnancy is driven into a growing of pro-atherogenic metabolic state ${ }^{[5,52]}$. Shortly after conception pregnant women develops a high cardiac output ${ }^{[53]}$, hypercoagulability ${ }^{[54]}$, and increased inflammatory activity $^{[55]}$. After 20 weeks there is insulin resistance ${ }^{[52,56]}$ and hyperlipidaemia ${ }^{[57]}$. Healthy women responds adequately and tolerates well physiologic changes during pregnancy, but woman with inherited or acquired predisposition to different chronic diseases may not tolerate pregnancy induced hormonal or hemodynamic changes ${ }^{[57]}$. These gestational changes are usually more pronounced in women who later develop preeclampsia. The effect of coexisting risk-factors are clearly confirmed in several studies. This is partly due to pre-existing, subclinical inflammatory and/or cardiovascular risk factors in "healthy" women who go on to develop preeclampsia ${ }^{[58]}$. These women are more likely to be overweight ${ }^{[59,60]}$ have higher lipid levels, higher blood pressure, insulin resistance and are more likely to have a thrombophilia, compared with women who go on to have a normotensive pregnancy.

Angiogenic factors also contribute to development of preeclampsia. Seems that maternal diseases (or predisposition) is related to anti-angiogenic factors sFlt-1 and sEng, released by an affected placenta. Are these anti-angiogenic proteins involved in development of the maternal diseases later is not clear, however could indicate the predisposition of development of cardiovascular abnormalities ${ }^{[2]}$.

Preeclampsia is associated with impairment of vascular function, impaired endothelial function, share some common features of development of atherosclerosis. The 498 women from the Epidemiology of Coronary Artery Calcification Study were evaluated for presence of subclinical coronary atherosclerosis using logistic regression model, up to $10.4 \%$ had history of hypertension during pregnancy, what also was associated with impairment of kidney function and coronary artery calcium score later during lifespan ${ }^{[22,61]}$.

Insulin resistance is developing physiologically in healthy pregnant women, however may remain after delivery and even progress in certain women with predisposition (because of acquired or inherited factors). In a population-based, retrospective cohort study for 1,010,068 pregnant women was determined twofold rise of risk of development of diabetes during up to 16.5 years after pregnancy, even in the absence of gestational diabetes. The presence of preeclampsia or gestational hypertension in women with gestational diabetes also significantly rises the lifelong risk of diabetes compared to gestational diabetes without preeclampsia or gestational diabete ${ }^{[21,62]}$ which is independent risk for future cardiovascular events.

Vascular wall seems that is responding to preeclampsia. Thus study preformed showed that Carotid Artery Intima-media thickening us reliably higher in women with preeclampsia, is reducing after delivery, but remain significantly higher in a year after delivery in women with previous preeclampsia ${ }^{[63]}$.

\section{CONCLUSION}

Cardiovascular morbidity is multifactorial, preclinical stage is starting in early ages, is linked to multiple risk-factors. Cardiovascular morbidity has several unique characteristics for women; pregnancy, gestational 
hypertension, preeclampsia/eclampsia are gender-specific risk-factors for further cardiovascular morbidity in women, which is possible to reveal in young ages and start prevention as early as possible. Seems abnormalities detected during pregnancy are linked to life-long cardiovascular morbidity, so pregnancyrelated morbidity starts to exceed concerns of obstetricians and takes the important part of primary care physicians and cardiologists as well. Is pregnancy just revealing or predisposing factor of development cardiovascular diseases is not still clear and to answer these questions more and more studies are required.

\section{DECLARATIONS}

\section{Authors' contributions}

Study design: Vakhtangadze T

Data collection: Gakhokidze N

Manuscript writing: Vakhtangadze T, Gakhokidze N

Manuscript review: Vakhtangadze T

Serching and evaluating the references: Khutsishvili M, Mosidze S

\section{Availability of data and materials}

Not applicable.

\section{Financial support and sponsorship}

None.

\section{Conflicts of interest}

All authors declared that there are no conflicts of interest.

\section{Ethical approval and consent to participate}

Not applicable.

\section{Consent for publication}

Not applicable.

\section{Copyright}

(C) The Author(s) 2019.

\section{REFERENCES}

1. Mozaffarian D, Benjamin EJ, Go AS, Arnett DK, Blaha MJ, et al. Heart disease and stroke statistics-2015 update: a report from the American Heart Association. Circulation 2015;131:e29-322.

2. Khan K, Wojdyla D, Say L, Gülmezoglu AM, Van Look PF. WHO analysis of causes of maternal death: a systematic review. Lancet 2006;367:1066-74.

3. Mosca L, Benjamin EJ, Berra K, Bezanson JL, Dolor RJ, et al. Effectiveness based guidelines for the prevention of cardiovascular disease in women-2011 update: a guideline from the American Heart Association. Circulation 2011;123:1243-62.

4. Shalimova A. Heart and vascular remodeling in essential hypertension and type 2 diabetes is dependent on genetic polymorphisms. Vessel Plus 2017;1:84-90.

5. Bilovol O. Predictors of hormonal and metabolic disorders of arterial hypertension and type 2 diabetes mellitus comorbidity. Vessel Plus 2017;1:22-8.

6. Roberts JM, August PA, Bakris G, Barton JR, Bernstein IM, et al. Hypertension in pregnancy: report of the American college of obstetricians and gynecologists' task force on hypertension in pregnancy. Obstet Gynecol 2013;122:1122-31.

7. Duley L. The global impact of pre-eclampsia and eclampsia. Semin Perinatol 2009;33:130-7.

8. Mancia G, Fagard R, Narkiewicz K, Redon J, Zanchetti A, et al. 2013 ESH/ESC Guidelines for the management of arterial hypertension. Journal of Hypertension 2013;31:1281-357.

9. Gifford RW, August PA, Cunningham G, Green LA, Lindheimer MD, et al. Report of the national high blood pressure education program working group on high blood pressure in pregnancy. Am J Obstet Gynecol 2000;183:S1-22.

10. ACOG technical bulletin. Hypertension in pregnancy. Number 219--January 1996 (replaces no. 91, February 1986). Committee on Technical Bulletins of the American College of Obstetricians and Gynecologists. Int J Gynaecol Obstet 1996;53:175-83. 
11. Melchiorre K, Sutherland GR, Liberati M, Thilaganathan B. Preeclampsia is associated with persistent postpartum cardiovascular impairment. Hypertension 2011;58:709-15.

12. Abalos E, Cuesta C, Grosso AL, Chou D, Say L. Global and regional estimates of preeclampsia and eclampsia: a systematic review. Eur J Obstet Gynecol Reprod Biol 2013;170;1-7.

13. Mackillop L. Pre-eclampsia: reducing the risk with calcium supplements. BMJ Clin Evid 2015;2015:1402.

14. Reyes LM, García RG, Ruiz SL, Broadhurst D, Aroca G, et al. Angiogenic imbalance and plasma lipid alterations in women with preeclampsia from a developing country. Growth Factors 2012;30:158-66.

15. Grandi SM, Vallée-Pouliot K, Reynier P, Eberg M, Platt RW, et al. Hypertensive disorders in pregnancy and the risk of incident cardiovascular disease. Paediatr Perinat Epidemiol 2017;31:412-21.

16. McDonald SD, Malinowski A, Zhou Q, Yusuf S. Cardiovascular sequelae of preeclampsia/eclampsia: a systematic review and metaanalyses. Am Heart J 2008;156:918-30.

17. Bellamy L, Casas JP, Hingorani AD, Williams DJ. Preeclampsia and risk of cardiovascular disease and cancer in later life: systematic review and meta-analysis. BMJ 2007;335:974.

18. Sabiri B, Moussalit A, Salmi S, Youssoufi S, Miguil M. Post-partum eclampsia: epidemiology and prognosis. Journal de Gynecologie Obstetrique et Biologie de la Reproduction 2007;36:276-80.

19. Regitz-Zagrosek V, Roos-Hesselink JW, Bauersachs J, Blomstrom-Lundqvist C, Cifkova R, et al. 2018 ESC guidelines for the management of cardiovascular diseases during pregnancy. Eur Heart J 2018;39:3165-241.

20. Wagner 1. Diagnosis and management of preeclampsia. Am Fam Physician 2004;70:2317-24.

21. Parra-Cordero M, Sepúlveda-Martínez A, Preisler J, Pastén J, Soto-Chacón E, et al. Role of the glucose tolerance test as a predictor of preeclampsia. Gynecol Obstet Invest 2014;78:130-5.

22. Powe CE, Levine RJ, Karumanchi SA. Preeclampsia, a disease of the maternal endothelium: the role of antiangiogenic factors and implications for later cardiovascular disease. Circulation 2011;21:2856-69.

23. Larsen WI, Strong JE, Farley JH. Risk factors for late postpartum preeclampsia. J Reprod Med 2012;35-8.

24. Karumanchi SA, Levine RJ. How does smoking reduce the risk of pre-eclampsia? Hypertension; 2010. pp. 1100-1.

25. Bartsch E., Medcalf KE, Park AL, Ray JG. Clinical risk factors for pre-eclampsia determined in early pregnancy: systematic review and meta-analysis of large cohort studies. BMJ 2016;353:11753.

26. McCormick AS, Wood A, Wee MY. Visual disturbances and seizures associated with pregnancy: a diagnostic dilemma and the role of radiological techniques as an aid to diagnosis. Int J Obstet Anesth 1999;8:184-8.

27. Saxena N, Bava A, Nandanwar Y. Maternal and perinatal outcome in severe preeclampsia and eclampsia. International journal of reproduction, contraception, obstetrics and ynecology. 2016:5:2171-6.

28. PSantos R, Correa VM, Modesto FG, Moutella FRD. Late-onset postpartum eclampsia: still a diagnostic dilemma. Hong Kong Med J 2008;14:60-3.

29. Munjuluri N, Lipman M, Valentine A, Hardiman P, Maclean AB. Postpartum eclampsia of late onset. BMJ 2005;331:1070.

30. Sibai BM. Etiology and management of postpartum hypertension-preeclampsia. Am J Obstet Gynecol 2012;206:470-5.

31. Al-Safi Z, Imudia AN, Filetti LC, Hobson DT, Bahado-Singh RO, MBA, et al. Delayed postpartum preeclampsia and eclampsia demographics, clinical course, and complications. Awonuga, MDObstet Gynecol 2011;118:1102-7

32. Douglas AKG, Redman CW. Eclampsia in the United Kingdom. British Medical Journal 1994;309:1395-1400.

33. Simcox LE, Ormesher L, Tower C, Greer IA. Pulmonary thrombo-embolism in pregnancy: diagnosis and management. Breathe 2015;11:282-9.

34. Vilchez G, Hoyos LR, Leon-Peters J, Lagos M, Argoti P. Differences in clinical presentation and pregnancy outcomes in antepartum preeclampsia and new-onset postpartum preeclampsia: Are these the same disorder? Obstet Gynecol Sci 2016;6:434-43.

35. Stuart JJ, Tanz LJ, Cook NR, Spiegelman D, Missmer SA. Hypertensive disorders of pregnancy and 10-year cardiovascular risk prediction. J Am Coll Cardiol 2018;72:1252-63.

36. Breetveld NM, Ghossein-Doha C, van Kuijk S, van Dijk AP, van der Vlugt MJ, et al. Cardiovascular disease risk is only elevated in hypertensive, formerly preeclamptic women. BJOG 2015;122:1092-100.

37. Bokslag A, Teunissen PW, Franssen C, van Kesteren F, Kamp O, et al. Effect of early-onset preeclampsia on cardiovascular risk in the fifth decade of life. Am J Obstet Gynecol 2017;216:523.e1-523.

38. Ros HS, Lichtenstein P, Bellocco R, Petersson G, Cnattingius S. Pulmonary embolism and stroke in relation to pregnancy: how can high-risk women be identified? Am J Obstet Gynecol 2002;186:198-203.

39. Todua F, Akhvlediani M, Vorobiova E, Tsivtsivadze G, Baramidze A. Homocysteine and D-dimer levels and multilayer computed tomography for diagnosing pulmonary artery thromboembolism. Sessel plus 2017; doi: 10.20517/2574-1209.2016.06.

40. Goel A, Maski MR, Bajracharya S, Wenger JB, Zhang D, et al. Epidemiology and mechanisms of de novo and persistent hypertension in the postpartum period. Circulation 2015;132:1726-33.

41. Grandi SM, Reynier P, Platt RW, Basso O, Filion K. The timing of onset of hypertensive disorders in pregnancy and the risk of incident hypertension and cardiovascular disease. Int J Cardiol 2018;270:273-5.

42. Soma-Pillay P, Catherine NP, Tolppanen H, Mebazaa A, Tolppanen H, et al. Physiological changes in pregnancy. Cardiovascular Journal of Africa 2016;27:89-94.

43. Chapman AB, Abraham WT, Zamudio S, Coffin C, Merouani A, et al. Temporal relationships between hormonal and hemodynamic changes in early human pregnancy. Kidney Int 1998;54:2056-63.

44. Sanghavi M, Rutherford JD. Cardiovascular physiology of pregnancy. Circulation 2014;130:1003-8.

45. Melchiorre K, Sutherland GR, Liberati M, Thilaganathan B. Preeclampsia is associated with persistent postpartum cardiovascular impairment. 2011;58:709-15.

46. Khong TY. Acute atherosis in pregnancies complicated by hypertension, small-for-gestational-age infants, and diabetes mellitus. Arch Pathol Lab Med 1991;115:722-5. 
47. Merck. Merck Manual 2018. https://www.merckmanuals.com/professional

48. Lykke JA, Langhoff-Roos J, Sibai BM, Funai EF, Triche EW, et al. Hypertensive pregnancy disorders and subsequent cardiovascular morbidity and type 2 diabetes mellitus in the mother. Hypertension 2009;53:944-51.

49. Levine RJ, Vatten LJ, Horowitz GL, Qian C, Romundstad PR, et al. Karumanc pre-eclampsia, soluble fms-like tyrosine kinase 1, and the risk of reduced thyroid function: nested case-control and population based study. BMJ 2009;17:39.

50. Hubel CA, Snaedal S, Ness RB, Weissfeld LA, Geirsson RT, et al. Dyslipoproteinaemia in postmenopausal women with a history of eclampsia. BJOG 2000;107:776-84.

51. Sattar N, Greer IA. Pregnancy complications and maternal cardiovascular risk: opportunities for intervention and screening. BMJ 2002;325:157-60.

52. Seely EW, Solomon CG. Insulin resistance and its potential role in pregnancy-induced hypertension. J Clin Endocrinol Metab 2003;88:2393-8.

53. Bosio PM, McKenna PJ, Conroy R, O’Herlihy C. Maternal central hemodynamics in hypertensive disorders of pregnancy. Obstet Gynecol 1999;94:978-84.

54. IA Greer. Thrombosis in pregnancy: maternal and fetal issues. Lancet 1999;10:1258-65.

55. Redman CW, Sacks GP, Sargent IL. Pre-eclampsia: an excessive maternal inflammatory response to pregnancy. Am J Obstet Gynecol 1999; 180:499-506.

56. Kuhl C. Insulin secretion and insulin resistance in pregnancy and GDM: implications for diagnosis and management. Diabetes 1991;40:18-24.

57. Martin U, Davies C, Hayavi S, Hartland A, Dunne F. Is normal pregnancy atherogenic? Clin Sci (Lond) 1999;96:421-5.

58. Redman CW, Sacks GP, Sargent IL. Pre-eclampsia: an excessive maternal inflammatory response to pregnancy. Am J Obstet Gynecol 1999;180:499-506.

59. Magnussen EB, Vatten LJ, Lund-Nilsen TI, Salvesen KA, Davey Smith G. Prepregnancy cardiovascular risk factors as predictors of preeclampsia: population based cohort study. BMJ 2007;335:978.

60. Romundstad PR, Magnussen EB, Davey Smith G, Vatten LJ. Hypertension in pregnancy and later cardiovascular disease: common antecedents? Circulation 2010;122:579-84.

61. Cassidy-Bushrow AE, Bielak LE, Rule AD, Sheedy PF, Turner ST, et al. Hypertension during pregnancy is associated with coronary artery calcium independent of renal function. J Womens Health (Larchmt) 2009;18:1709-16.

62. Feig DS, Shah BR, Lipscombe LL, Wu CF, Ray JG, et al. Preeclampsia as a risk factor for diabetes: a population based cohort study. PLoSMed 2013;10.

63. Akhter T, Wikström AK, Larsson M. Individual common carotid artery wall layer dimensions, but not carotid intima-media thickness, indicate increased cardiovascular risk in women with preeclampsia. Circ Cardiovasc Imaging 2013;6:762-8. 